\section{P13.14 EDUCATING WOMEN ABOUT NORMAL FEMALE GENITAL APPEARANCE: THE EFFECTIVENESS OF TWO BRIEF INTERVENTIONS}

G Sharp*, M Tiggemann. School of Psychology, Flinders University

10.1136/sextrans-2015-052270.512

Introduction There has been a rapid increase in the demand for labial reduction surgery or labiaplasty in recent years. Labiaplasty is commonly performed for aesthetic reasons, more specifically; patients desire a smooth vulvar surface with 'tucked in' labia minora. In general, women are not aware of the great diversity in normal female genital appearance and believe that the 'tucked in' look shown in the media is the norm. The current study aimed to educate women from the general Australian community about the large variation in normal female genital appearance in order to improve their knowledge and also their attitudes towards their own genital appearance.

Methods Two freely available online resources were employed as educational interventions. The first intervention involved viewing a photographic array of normal female genitals and the second consisted of a short video addressing the digital airbrushing of women's labia minora in media images. A sample of 136 women aged 18-49 years were randomly assigned to view the photographs, video, both the photographs and video, or neither. Results It was found that the video intervention significantly increased women's perceptions of the diversity of female genital appearance, as well as their knowledge of the digital airbrushing of genital images. Although there was no effect of the interventions on women's attitudes towards their own genital appearance, women who viewed the video indicated they would assist other women with genital appearance concerns by educating them about the digital airbrushing of media images.

Conclusion The results suggest that health practitioners could potentially use this short video to educate women who are concerned about the normality of their genital appearance and are considering labiaplasty. Moreover, this video could be used in sexual education programs in schools with young girls to potentially prevent the development of genital appearance concerns as they mature.

Disclosure of interest statement Nothing to declare.

\section{P14 - Social sciences, policy and programmes}

\section{P14.01 IS KNOWLEDGE POWER? ASSOCIATIONS BETWEEN CHLAMYDIA KNOWLEDGE AND SEXUAL PRACTICES IN YOUNG AUSTRALIAN ADULTS: FINDINGS FROM THE AUSTRALIAN CHLAMYDIA CONTROL EFFECTIVENESS PILOT (ACCEPT)}

${ }^{1}$ A Vaisey*, ${ }^{1} \mathrm{JL}$ Goller, ${ }^{2} \mathrm{~A}$ Yeung, ${ }^{1} \mathrm{~A}$ Wood, ${ }^{1} \mathrm{AL}$ Bingham, ${ }^{3} \mathrm{RJ}$ Guy, ${ }^{4} \mathrm{M}$ Temple-Smith, ${ }^{1} \mathrm{JS}$ Hocking. 'Centre for Epidemiology and Biostatistics, Melbourne School of Population and Global Health, University of Melbourne; ${ }^{2}$ School of Public Health and Community Medicine, University of New South UK; ${ }^{3}$ The Kirby Institute, University of New South UK; ${ }^{4}$ General Practice and Primary Health Care Academic Centre, University of Melbourne

\subsection{6/sextrans-2015-052270.513}

Introduction Chlamydia knowledge and sexual practice data were collected from 16-29 year olds during the ACCEPt baseline chlamydia prevalence survey. We report patient chlamydia knowledge and explore whether knowledge is associated with reported sexual practices.

Methods A consecutive sample of 16-29 year olds was recruited from participating general practice clinics. Participants were tested for chlamydia and completed a demographic, sexual practice and knowledge questionnaire. Chlamydia knowledge was assessed via nine true/false questions. Two markers of sexual risk were assessed: two or more partners in the last 12 months and any concurrent sexual partners in the last 12 months. Logistic regression was used to investigate associations between knowledge items and sexual risk. All analyses were adjusted for participant gender and age.

Results A total of 4261 patients $(72 \%$ female) participated (response rate $70 \%$ ). $35 \%$ reported two or more partners in the last 12 months and 15\% reported concurrency. 49\% answered seven or more questions correctly and 16\% answered four or fewer questions correctly. Participants were less likely to report concurrent sexual partners if they correctly answered questions about the fact that chlamydia is often asymptomatic $(\mathrm{OR}=$ 0.84 ; 95\% CI: $0.73-0.96$; $\mathrm{p}<0.01$ ), that chlamydia is transmissible via oral sex $(\mathrm{OR}=0.88 ; 95 \% \mathrm{CI}: 0.81-0.95 ; \mathrm{p}<0.01)$ and that the Pap smear does not test for chlamydia $(\mathrm{OR}=0.89$; 95\% CI: $0.82-0.97 ; \mathrm{p}<0.01)$. Participants were less likely to report two or more partners in the last 12 months if they correctly answered questions about how common chlamydia is (OR $=0.91 ; 95 \%$ CI: $0.84-0.98 ; \mathrm{p}<0.01)$, the fact that chlamydia is transmissible via oral sex (OR $=0.91 ; 95 \%$ CI: 0.85-0.96; $\mathrm{p}$ $<0.01)$ and that the Pap smear does not test for chlamydia (OR $=0.93 ; 95 \%$ CI: 0.87-0.98; $\mathrm{p}<0.01$ ).

Conclusion Chlamydia knowledge appears to be associated with some reported sexual risk practices. Findings can feed into education and behaviour change strategies aimed to control chlamydia.

Disclosure of interest statement ACCEPt was commissioned and funded by the Australian Government Department of Health and Ageing. Additional funding has been received from the National Health and Medical Research Council, the Victorian Department of Health and NSW Health.

\section{P14.02 SYSTEMATIC REVIEW: DOES A POSITIVE HUMAN PAPILLOMAVIRUS VACCINATION STATUS INCREASE THE RISK OF UNSAFE SEXUAL HEALTH PRACTICE IN AUSTRALIAN WOMEN?}

${ }^{1,2} \mathrm{~N} \mathrm{Kuk}^{*},{ }^{1,2} \mathrm{~J}$ To, ${ }^{1,3} \mathrm{C}$ McBride, ${ }^{1,2} \mathrm{~A}$ Hong, ${ }^{1,2} \mathrm{E} \mathrm{Ng},{ }^{1,3} \mathrm{~N} \mathrm{Li}, 1,2 \mathrm{M}$ Teo, ${ }^{1,2} \mathrm{~V}$ Zhang, ${ }^{1,4} \mathrm{D}$ Velasco, 1,2 L Ling, ${ }^{1,2} \mathrm{Y}$ Sun, ${ }^{1,3} \mathrm{M}$ Keem. ${ }^{1}$ Asian Medical Students Association (Australian Chapter); ${ }^{2}$ Monash University, VIC, Australia; ${ }^{3}$ The University of Melbourne, VIC, Australia; ${ }^{4}$ Deakin University, VIC, Australia

\subsection{6/sextrans-2015-052270.514}

Background The human papillomavirus (HPV) is a sexually transmitted infection responsible for the majority of cervical and anogenital cancers. HPV vaccination aims to reduce this risk especially against the four most influential strains, HPV genotype 6, 11, 16 and 18. However, it is not known if HPV vaccination also exerts an influence over sexual behaviour. The objective of this study is to investigate whether a positive HPV vaccination increases the risk of engaging in unsafe sexual health practice. Methods A systematic literature search was conducted in MEDLINE, Scopus, Embase, Discovery and Google Scholar, from the $1^{\text {st }}$ of January 2007 to the $1^{\text {st }}$ of March 2015. Titles, abstracts and in case of relevance, full-texts, were screened according to predefined inclusion and exclusion criteria. Relevant study 